\title{
Quantitative Analysis of L-Dopa \\ (L-3,4-Dihydroxyphenylalanine) Content in Extracts of Various Products from Velvet Bean (Mucuna pruriens (L.) DC.) Tempe Processing
}

\section{SRI RETNO DWI ARIANI ${ }^{1,2 *}$, SABIRIN MATSJEH ${ }^{2}$, MUSTOFA $^{3}$ and BAMBANG PURWONO ${ }^{2}$}

'Department of Chemistry Education, Faculty of Teacher Training and Education, Sebelas Maret University, JI Ir. Sutami 36A, Kentingan, Surakarta, 57126, Indonesia.

${ }^{2}$ Department of Chemistry, Faculty of Mathematic and Natural Sciences, Gadjah Mada University, Sekip Utara PO BOX BLS 21, Yogyakarta, 55281, Indonesia.

${ }^{3}$ Department of Pharmacology and Toxicology, Faculty of Medicine,

Gadjah Mada University, Jl. Sekip Utara Yogyakarta, 55281, Indonesia.

*Corresponding author: E-mail: sriretnodwiariani@yahoo.co.id

http://dx.doi.org/10.13005/ojc/320611

(Received: March 12, 2016; Accepted: October 09, 2016)

\begin{abstract}
The research was focused on quantitative analysis of L-Dopa content in extracts of various products from velvet bean tempe processing. The procedures of velvet bean tempe processing were dehulling, soaking, steaming, inoculating with Raprima tempe inoculum that contain Rhizopus oligosporus NRRL 2771, packaging and fermenting at room temperature for $24,48,72$ and $96 \mathrm{~h}$, respectively. The products of velvet bean tempe processing were extracted with ethyl acetate followed by ethanol. Quantitative analysis of L-Dopa content in the extracts was performed by validated TLCDensitometric method. Extracts of dehulled velvet bean, pre-fermented velvet bean, velvet bean fermented for $24,48,72$ and 96 h contained L-Dopa as much as $26.24 \%, 40.20 \%, 0.47 \%, 2.67 \%$, $3.27 \%$ and $3.55 \%(\mathrm{w} / \mathrm{w})$, respectively. From this report, we had useful information to develope a new nutraceutical from the product of velvet bean tempe processing with expected health benefits.
\end{abstract}

Keywords: L-Dopa, velvet bean, Mucuna pruriens (L.) DC., tempe.

\section{INTRODUCTION}

Velvet bean (Mucuna pruriens (L.) DC.) is commonly known as koro benguk in Indonesia ${ }^{1}$ and cowhage or atmagupta in India ${ }^{2}$. In taxonomy, velvet bean belongs to the family Fabaceae

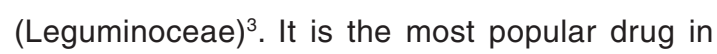
Indian Ayurvedic medicine and is used for dysentry, diarrhea, snake bite, sexual debility, cough, tuberculosis, impotence, rheumatic disorders, muscular pain, gonorrhea, sterility, gout, delirium, dysmenorrhea, diabetes and cancer ${ }^{4}$. 
In Indonesia, velvet bean grows well in marginal dry land areas and is one of Indonesia's indigenous beans ${ }^{5}$. In Central Java, Indonesia, there is a common way to process velvet bean seeds into tempe. Tempe is a traditional food from Central Java, usually made from soybean, but velvet bean is also suitable for tempe production ${ }^{5,6,7}$. The essential fungus involved in tempe fermentation is Rhizopus oligosporus, although someother organisms are usually found in inoculum. Other Rhizopus species such as $R$. arrhizus, $R$. stolonifer and $R$ oryzae may grow, in addition to other genera such as Mucor and Aspergillus ${ }^{8}$. During tempe processing, there are valuable changes not only in the increase of nutritional values of some nutrients in beans, but also in the development of vitamins, phytochemicals and antioxidative constituents ${ }^{7}$. Handajani said that compared with velvet bean as a raw material, velvet bean tempe had the higher isoflavones (glycitein, daidzein, factor-2) and also fat, carbohydrate and fibre levels. $\mathrm{HCN}$ content in velvet bean could be eliminated by appropriate soaking, boiling and fermenting 5 . Nowadays in Indonesia, velvet bean and velvet bean tempe still have a low social economic status. Great attention would be given by researchers to develop them as material for nutraceutical production.

L-Dopa (L-3,4-dihydroxyphenylalanine) is the main bioactive compound of velvet bean ${ }^{9,10,11}$ and has been reported as an active ingredient pharmacologically, including for treatment parkinsons' disease ${ }^{12}$, antioxidant activity ${ }^{13}$ and the direct precursor to the neurotransmitter dopamine ${ }^{14}$. Egounlety (2003) stated that pre-fermentation and fermentation process to velvet bean could reduce L-Dopa content of its. The pre-fermented velvet bean process (the beans were boiled for $45 \mathrm{~min}$, dehulled, soaked for $24 \mathrm{~h}$, and then boiled again in $45 \mathrm{~min}$ ) reduced L-Dopa content in velvet bean (from $6.360 \%$ in velvet bean to $0.639 \%$ in pre-fermented velvet bean). Further, reduction was obtained during fermentation. All the fermented products contained low levels of L-Dopa (often $<0.1 \%$ dry weight). According to Egounlety (2003), the weakness of this velvet bean tempe processing was limited in large scale production because the boiled beans still dehulled by hand (manual procedure) $)^{15}$.
In Central Java Indonesia, there are many variations of velvet bean tempe production from one region and one producer to others, because there is no standard process for producing of the velvet bean tempe ${ }^{7}$. The method of velvet bean tempe processing in our research was based on one of the methods of the velvet bean tempe industry in Indonesia, i.e. dehulling with machine to the raw velvet bean, soaking, steaming, inoculating with Raprima tempe inoculum that contain Rhizopus oligosporus NRRL 2771, packaging and fermenting at room temperature. The method was different from the velvet bean tempe processing by Egounlety's research (2003). Researchers do not know the effect of this velvet bean tempe processing to L-Dopa content in the extracts, so it was necessary to evaluate how many levels of L-Dopa of its. The research was focused on quantitative analysis of L-Dopa content in extracts of the products from velvet bean tempe processing. In this research, TLCDensitometric method was developed and validated to quantitative analysis of L-Dopa content in extracts. Thin layer Chromatography (TLC), also known as planar chromatography (PC), is one of the oldest methods in analytical chemistry. This method was simple, sensitive, saving time, economical, fast and suitable for any laboratory ${ }^{16-18}$.

\section{MATERIALS AND METHODS}

\section{The seed collection and identification}

Velvet bean (Mucuna pruriens (L.) DC.) was obtained from Sekar Aji Farmer Group in Manyaran Wonogiri, Central Java, Indonesia and authenticated in the Laboratory of Plant Taxonomy, Faculty of Biology, Gadjah Mada University, Indonesia.

\section{Inoculum of fermentation}

Raprima tempe inoculum was produced by Aneka Fermentasi Industri (AFI) in Bandung, West Java, Indonesia which contains Rhizopus oligosporus NRRL 2771.

\section{Chemicals}

L-Dopa standard was purchased from Sigma-Aldrich Chemical Co. (Germany). All other chemicals and reagents used were of analytical grade. 


\section{Preparation of samples}

Dehulled velvet bean, pre-fermented velvet bean and velvet bean tempes with variation time fermentation (24, 48, 72 and 98 h, respectively) were the samples. Each of samples made from 100 $\mathrm{g}$ of dehulled velvet bean as a raw material. The steps of velvet bean tempe processing were as follows: velvet bean seeds were dehulled to make dehulled velvet bean. We took $100 \mathrm{~g}$ dehulled velvet<smiles>NC(Cc1ccc(O)c(O)c1)C(=O)O</smiles>

Fig. 1: The structure of L-Dopa

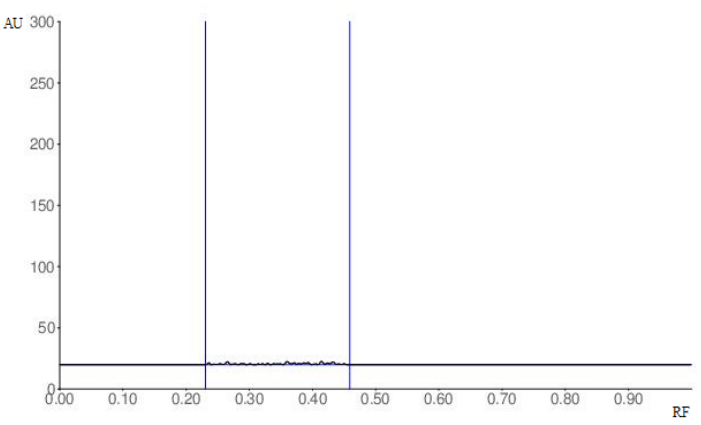

(a) bean and grounded it to make dehulled velvet bean powder as the first sample. Further, $500 \mathrm{~g}$ dehulled velvet bean were soaked for $72 \mathrm{~h}$ with removal and replacement of water after $6 \mathrm{~h}$. The soaked velvet bean was dried and steamed in boiling water for 90 min. After that, we cooled it by spreading in a flat tray at room temperature and we found pre-fermented velvet bean. We divided it into 5 portions. One portion of pre-fermented velvet bean was grounded by blender into slurry as the second sample. Solid state fermentation was performed by inoculated to another portion of pre-fermented velvet bean with Raprima tempe inoculum and packed in perforated plastic and fermented on the racks at room temperature for 24 , 48,72 and 96 h, respectively. Subsequently, each of velvet bean tempe with variation time fermentation was grounded by blender into slurry as the third, fourth, fifth and sixth samples, respectively ${ }^{19}$.

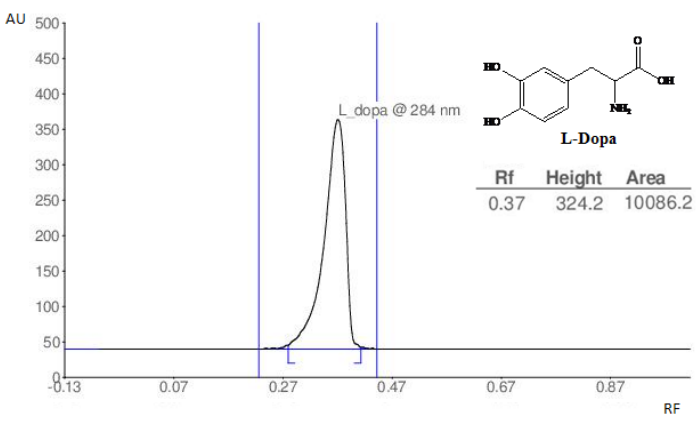

(b)

Fig. 2: The densitograms of (a) blank and (b) L-Dopa standard in concentration $2.500 \mu$ spot $^{-1}$ at $R F=0.37$

The Calibration curve of L-Dopa

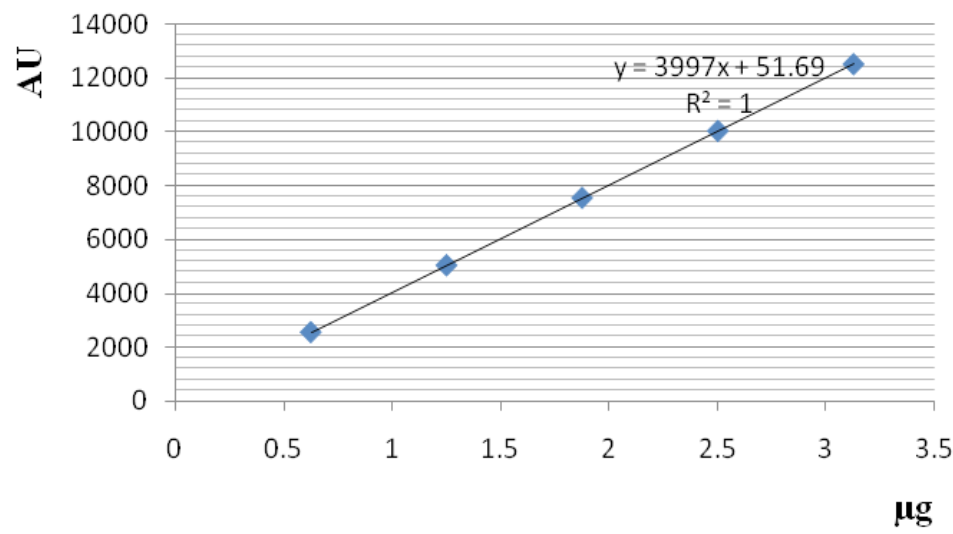

Fig. 3: The calibration curve of L-Dopa standard 


\section{Extraction of samples}

The dehulled velvet bean, pre-fermented velvet bean and velvet bean tempes with variation time fermentation time $(24,48,72$ and $98 \mathrm{~h}$, respectively) were defatted with ethyl acetate by maceration method and stirred for $6 \mathrm{~h}$ at room temperature. Maceration was terminated when the last extract turned colourless. Each of defatted material was extracted with $70 \%$ ethanol by maceration method and stirred at room temperature for $6 \mathrm{~h}$. The residual material was removed by filtration and the filtrate was pooled. Extraction was terminated when the last extract was colourless. The filtrate was concentrated by a Buchi R-200 rotary vacuum evaporator at $60^{\circ} \mathrm{C}$, collected and weighed. The procedure was repeated in triplicate. All the samples were stored in a refrigerator at $4^{\circ} \mathrm{C}$ and used in TLC-Densitometric analysis.

Table 1: The result of the development and validation of TLC-Densitometric method for quantitative analysis of L-Dopa content in extracts of various products from velvet bean tempe processing

\begin{tabular}{|c|c|}
\hline Parameters & L-Dopa \\
\hline Plate & Silica gel GF 254 \\
\hline Mobile phase & $\begin{array}{l}\text { butanol:glacial acetic acid:water } \\
(6.0: 1.0: 1.0, \mathrm{v} / \mathrm{v} / \mathrm{v})\end{array}$ \\
\hline Detection wavelength & $284 \mathrm{~nm}$ \\
\hline RF value & 0.37 \\
\hline Calibration range $\left(\mu\right.$ g.spot $\left.^{-1}\right)$ & $0.625-3.750$ \\
\hline Regression equation & $y=3997 x+51.69$ \\
\hline Correlation coefficient & 1.00 \\
\hline Limit of Detection (LOD) (ng.spot ${ }^{-1}$ ) & 7.95 \\
\hline Limit of Quantification (LOQ) (ng.spot ${ }^{-1}$ ) & 26.5 \\
\hline Repeatability (intraday precision) (\% RSD) & Precise $(0.74)$ \\
\hline Intermediate precision (interday precision) (\% RSD) & Precise $(0.33)$ \\
\hline Accuracy (Mean of \% recovery) & Accurate (100.04) \\
\hline Ruggedness & Rugged \\
\hline Robustnes & Robust \\
\hline
\end{tabular}

Table 2: L-Dopa content (\%) w/w in extracts of various products from velvet bean tempe processing

\begin{tabular}{lcc}
\hline Sample & $\begin{array}{c}\text { L-Dopa content(\%) } \\
\text { w/w (of dehulled } \\
\text { velvet bean as a } \\
\text { raw material) } \\
\text { Mean } \pm \text { \%RSD }\end{array}$ & $\begin{array}{c}\text { L-Dopa content } \\
\text { (\%) w/w } \\
\text { (of extract) }\end{array}$ \\
\hline Extract of dehulled velvet bean & Mean \pm \%RD \\
Extract of pre-fermented velvet bean & $0.83 \pm 1.40^{\mathrm{e}}$ & $26.24 \pm 1.56^{\mathrm{d}}$ \\
Extract of velvet bean fermented for 24 h & $0.94 \pm 1.07^{\mathrm{d}}$ & $40.20 \pm 0.62^{\mathrm{e}}$ \\
Extract of velvet bean fermented for 48 $\mathrm{h}$ & $0.10 \pm 1.15^{\mathrm{a}}$ & $0.47 \pm 1.27^{\mathrm{a}}$ \\
Extract of velvet bean fermented for 72 $\mathrm{h}$ & $0.57 \pm 0.26^{\mathrm{b}}$ & $2.67 \pm 0.14^{\mathrm{b}}$ \\
Extract of velvet bean fermented for $96 \mathrm{~h}$ & $0.68 \pm 0.68^{\mathrm{b}, \mathrm{c}}$ & $3.27 \pm 0.21^{\mathrm{c}}$ \\
& $0.62 \pm 0.73^{\mathrm{c}}$ & $3.55 \pm 0.12^{\mathrm{c}}$ \\
\hline
\end{tabular}

Values are expressed as mean $\pm \% R S D(n=3)$; Means with the same superscript letter(s) along the same column are not significantly different $(P<0.05)$ 


\section{TLC-Densitometric instrumentation}

The chromatography was performed on TLC plate silica gel GF 254 from Merck Chemical Co. (Germany). The mobile phase consisted of butanol:glacial acetic acid:water (6.0:1.0:1.0, $\mathrm{v} / \mathrm{v} / \mathrm{v})$. Previously, time for saturation $45 \mathrm{~min}$, the average of development time was $60 \mathrm{~min}$ and time from chromatography to scanning was 10 min. Densitometric scanning was performed at wavelength $284 \mathrm{~nm}$ with a Camag TLC Scanner 3 in absorbance mode operated by winCATS software.

\section{Validation of TLC-Densitometric method}

Validation of the method was performed according to the United States Pharmacopeia (USP) and International Conference on Harmonization $(\mathrm{ICH})$ by checking the parameters of linearity, limit of detection (LOD), limit of quantification (LOQ), repeatability (intraday precision), intermediate precision (interday precision), accuracy, ruggedness, and robustness ${ }^{20-21}$

The procedure for preparing L-Dopa standard solution was approximately $62.5 \mathrm{mg}$ L-Dopa reference standard were accurately weighed and transferred into a $100 \mathrm{ml}$ volumetric flask, dissolved and diluted to volume with aquabidest to obtain a solution of $625 \mu \mathrm{g} \mathrm{ml}^{-1}$.

The linearity of the method was evaluated at six different concentration levels. Each amount was applied three times and the plates were developed under optimized mobile phase. Peak area versus corresponding amount of L-Dopa was used to construct calibration plot. The sensitivity of the method was determined by calculating the limit of detection (LOD) and limit of quantification (LOQ) of L-Dopa. The precision of the method was carried out by repeatability and intermediate precision. Repeatability (intraday precision) was validated by analyzing L-Dopa standard for repeating three times on the same day. Intermediate precision (interday precision) was validated by analyzing L-Dopa standard daily for three days. The accuracy of developed method was expressed by the recovery percentage of three different concentration levels for repeating three times. The ruggedness of the current method was determined by analyzing L-Dopa standard for repeating six times by two analysts in the same laboratory. The robustness was studied in triplicates by making deliberate small changes at different parameters of the current method. The variables involved changes in the mobile phase composition (butanol:glacial acetic acid:water (6.0: $0.9: 0.9,6.0: 1.0: 1.0,6.0: 1.1: 1.1, \mathrm{v} / \mathrm{v} / \mathrm{v})$, scanning time of chromatography (5, 10, $15 \mathrm{~min})$ and saturation time $(40,45,50 \mathrm{~min})^{18,20-24}$.

\section{Quantitative analysis of L-Dopa content}

Quantitative determination of L-Dopa content in extracts of dehulled velvet bean, prefermented velvet bean and velvet bean tempes with variation time fermentation $(24,48,72$ and $96 \mathrm{~h}$, respectively) were performed by validated TLCDensitometric method. WinCATS software was used for peak area measurement and data processing ${ }^{23}$. Quantification was based on peak areas were plotted against concentration. Data were expressed as mean $\pm \% R S D$ with $n=3$. Statistical analysis was done using one-way analysis of variance and Duncan's multiple range test using the one-way program in the SPSS package. Differences were considered statistically significant at $P<0.05^{25}$.

\section{RESULT AND DISCUSSION}

\section{Preparation of samples}

The velvet bean tempe processing involved dehulling velvet bean, soaking for $3 \times 24$ $h$ with removal and replacement of water after 6 h, steaming for 90 min, inoculating with Raprima tempe inoculum, packaging in perforated plastic and fermenting at room temperature. The velvet bean tempe processing yielded 6 samples consist of dehulled velvet bean, pre-fermented velvet bean and velvet bean tempes with variation time fermentation (24, 48, 72 and 96 h, respectively). Furthermore, those samples were extracted with ethyl acetate (defatted process) and then with ethanol 70\%. The usage of the mentioned solvents because according to USP, ethyl acetate and ethanol are categorized in the third class solvents that at normal level to be accepted in pharmaceutical. There are no long-term toxicity or carcinogenicity studies, less toxic in acute or short-term studies and negative in genotoxicity studies $^{26}$.

\section{Validation TLC-Densitometric method}

The development and validation of TLC-Densitometric was done first before taking a 
measurement of the L-Dopa content in extracts of various products from velvet bean tempe processing. The structure of L-Dopa can be seen in Fig.1. The densitograms of blank and L-Dopa standard in concentration $2.500 \mu$ spot $^{-1}$ at $\mathrm{RF}=0.37$ were given in Fig. 2. The calibration curve could be seen in Fig. 3. The result of the developed and validated TLC-Densitometric method was presented in Table 1.

The repeatability (intraday precision), intermediate precision (interday precision), ruggedness and robustness tests were acceptable if the parameter for the peak area had the percentage of RSD values $\leq 2.00 \%$. The accuracy was received (indicating good accuracy of the current method) if percentage of recoveries were in the range of 98.00$102.00 \%$ 20-21,27.

\section{Quantitative analysis of L-Dopa content}

The validated method was applied to quantitative analysis of L-Dopa content in extracts of dehulled velvet bean, pre-fermented velvet bean and velvet bean fermented for 24, 48, 72 and $96 \mathrm{~h}$, respectively. The result was presented in Table 2 .

In the fermentation for $96 \mathrm{~h}$, the process was terminated because the velvet bean fermentation product became rotten. This study demonstrated that compared with all of the extracts from Egounlety's research (2003), all of the extracts from this research had higher content of L-Dopa. The differences between the method of velvet bean tempe production in our research and the Egounlety's method were without boiling before dehulling and replaced boiling with steaming. All of the extracts from velvet bean tempes (fermented for 24, 48, 72 and $96 \mathrm{~h}$, respectively) contained low levels of $L$-Dopa, ranging from $0.47 \%$ to $3.55 \% \mathrm{w} / \mathrm{w}$. In our research, extract of pre-fermented velvet bean had the highest content of L-Dopa $(40.20 \% \mathrm{w} / \mathrm{w})$. This extract had a good prospect to be developed as a material for production of a new nutraceutical that has a high content of L-Dopa with expected health benefits. This research needs to be followed for evaluation of in vitro and in vivo biological activities.

\section{CONCLUSION}

Extracts of dehulled velvet bean, prefermented velvet bean, velvet bean fermented for $24,48,72$ and $96 \mathrm{~h}$ (the various products from velvet bean tempe processing) contained L-Dopa as much as $26.24 \%, 40.20 \%, 0.47 \%, 2.67 \%, 3.27 \%$ and $3.55 \%(w / w)$, respectively.

\section{ACKNOWLEDGMENTS}

This research was supported by Dissertation and New Doctoral Grant and financed by DIPA PNBP Sebelas Maret University Surakarta, Central of Java, Indonesia, Contract Number : 501/UN27.11/ PN/2014.

\section{REFERENCES}

1. Kasmidjo, R.B. Tempe Mikrobiologi dan Biokimia Pengolahan serta Pemanfaatannya, PAU Pangan dan Gizi UGM, Yogyakarta, 1990, 80.

2. Sing, R.M.; Saini, P.K.; Mathur, S.C.; Singh, G.N.; Kumar, S. International Journal of Green Pharmacy. 2010, July-September, 156-158.

3. Lampariello, L.R.; Cortelazzo, A.; Guerranti, R.; Sticozzi, C.; Valacchi, G. J. Tradit. Complement. Med. 2012, 2, 4, 331-339.

4. Taylor, L. Technical Data Report for Velvet bean Mucuna pruriens. Sage Press, Inc. Austin, 2003, 1-2.

5. Handayani, S. Asia Pacific J. Clin. Nutr. 2001, 10, 3, 222-225.
6. Watanabe, N.; Fujimoto, K.; Aoki, H. Int. J. Food Sci. Nutr. 2007, 58, 8, 577-587.

7. Astuti, M.; Meliala, A.; Dalais, F.S.; Wahlqvist, M.L. Asia Pacific J. Clin. Nutr. 2000, 9, 4, 322325.

8. Pawiroharsono, S. Microbiological Aspect of Tempe, The Complete Handbook of Tempe, ed. Agranoff, J., The American Soybean Association Southeast Asia Regional, Singapore, 1999, 93-101.

9. Siddhuraju, P.; Becker K. Food Chemistry, 2001, 72, 3, 389-394.

10. Vachhani, U.D.; Trivedi, M.N.; Bajaj, A.; Shah, C.P. Research Journal of Pharmaceutical, Biological and Chemical Sciences. 2011, 2, 
2, 389-396.

11. Sampath, V.; Mohamed, F.K.; Mani, N.; Babu, U.V. International Journal Pharmacognosy and Phytochemical Research. 2013, 5, 4, 259-262.

12. Hussian, G.; Manyam, B.V. Phytother. Res. 1997, 11, 6, 419-423.

13. Spina, M.B.; Cohen, G. J. Pharmacol. Exp. Ther. 1988, 247, 502-507.

14. Rani, N.; Joy, B.; Abraham, T.E. Pharm. Biol. 2007, 45, 48-53.

15. Egounlety, M. Tropical and Subtropical Agroecosystems. 2003, 1, 173-181.

16. Abdelwahab, N.S.; Ali, N.W.; Abdelkawy, M.M.; Elgebaly, A.M. Asian Journal of Biomedical and Pharmaceutical Sciences. 2014, 4, 30, 26-33.

17. Dolowy, M.; Pyka, A. Acta Poloniae $n$ Drug Research. 2014, 71, 6, 922-932.

18. Patel, M. Asian J. Pharm. Ana. 2014, 4, 2, 57-77.

19. Ariani, S.R.D. Biosmart. 2003, 5, 1, 8-12.

20. International Conference on Harmonization
(ICH) of Technical Requirements for the Registration of Pharmaceuticals for Human Use. Validation on Analytical Procedures: Text and Methodology Q2 (R1), http://www.ich.org. 1996.

21. USP 37-NF 32. 1225 Validation of Compendial Procedures, http://www.hmc.usp.org. 2014.

22. Vyas, A.; Jain, V.; Singh, D.; Singh, M.; Shukla, S.S.; Pandey, R.; Swarnlata, S.; Saraf, S. Oriental Journal of Chemistry. 2011, 27, 1, 301-304.

23. Singh, A.; Khan, M.H. Oriental Journal of Chemistry. 2014, 30, 1, 395-399.

24. Raina, A.P.; Khatri, R. Indian Journal of Pharmaceutical Sciences. 2011, 73, 4, 459462.

25. Chang, C.T.; Hsu, C.K.; Chou, S.T.; Chen, Y.C.; Huang, F.S.; Chung, Y.C. Int. J. Food Sci. Nutr. Tech. 2009, 44, 799-806.

26. USP. Residual Solvents, https://www.mc.usp. org, 2007.

27. Panigrahy, U.P.; Reddy, S.K. Oriental Journal of Chemistry. 2015, 31, 3, 1489-1507. 